\title{
2
}

\section{$\therefore$ Forms of Life and Artistic Practices}

If it is true, as Wittgenstein puts it in his most succinct formulation of this point, that "to imagine a language means to imagine a form of life," and if it is also true that art is in at least some sense a language, then it would be difficult to avoid the conclusion that to imagine an art form means to imagine a form of life. ${ }^{1}$ But before hastening toward any such conclusion, and certainly before knowing what such a conclusion in fact means, we must first explore what Wittgenstein meant by the phrase "form of life," and moreover what it means to imagine a language. Any incremental understanding gained on this matter holds unquestionable value for its power to cast light both on the analogy between art and language and on the issues surrounding the phrase "a form of life." Too of ten these issues are only vaguely attached to the phrase, but their importance to aesthetics is quite clear, for they include such matters as the significance of rituals to thought and feeling, the primitive and instinctive foundations of language, the point at which explanations come to an end, the notion of the mastering of a tech-

1. Ludwig Wittgenstein, Philosophical Investigations, 3d ed., trans. G. E. M. Anscombe (New. York: Macmillan, 1952), sec. 19. The definitive succinct statement of this position is found in Richard Wollheim, Art and Its Objects, $2 \mathrm{~d}$ ed. (Cambridge: Cambridge University Press, 1980), sec. 45-58. 
nique, the immediate expression of emotion within human contexts, and the larger idea of a linguistic community.

\section{The Concept of a Form of Life}

Immediately preceding the claim that to imagine a language is to imagine a form of life, Wittgenstein says, "It is easy to imagine a language consisting only of orders and reports in battle.-Or a language consisting only of questions and expressions for answering yes and no. And innumerable others" (Philosophical Investigations,, sec. 19). This passage clearly connects the notion of a form of life to that of a language-game, but in a sense it does so too well, for it has suggested to some that they are interchangeable, and thus at least roughly equivalent. They are not. Wittgenstein does reinforce the connection between these two notions, but he also provides good reason for doubting their identity: "Here the term 'language-game' is meant to bring into prominence the fact that the speaking of language is part of an activity, or of a form of life" (PI, sec. 23). Thus we might well think of a language-game in which the outer expressive limits are marked by a small set of questions and the answers "yes" and "no," or another in which only battle-orders and reports are exchanged, so that to think beyond this range of expression, from within this game, would be to try to give propositional form to the ineffable. We are thus in possession of a rough idea of what it is to imagine a language-game (but not yet, to be sure, a language), and we are also similarly in a position to see that to imagine a languagegame requires a set of roots reaching down into human action and practices. ${ }^{2}$ Speaking is, indeed, an instance of, or part of,

2. See Renford Bambrough, "The Roots of Moral Reason," in Gewirth's Ethical Rationalism, ed. Edward Regis, Jr. (Chicago: University of Chicago Press, 1984); I am also here indebted to his lecture "The Roots of Critical Reason," 
activity; what Wittgenstein opposes here is the view that language does float freely, without roots to action and practice, "above" the world to which it refers. A language-game, then, is, as it involves speaking, a part of an activity; and as an activity it is part of-but not wholly identical with-a form of life.

We find another piece of the puzzle in the next appearance of the phrase, specifically in the erroneous ways of the interlocutor. The interlocutor, always quick to think within the confines of traditional philosophical categories, asks, "So you are saying that human agreement decides what is true and what is false?" (PI, sec. 241). That is to say, is it not true, with words on one side and the world on the other, that truth is merely a function of the agreements implicitly resident within our language? This naive-conventionalist account is as quickly not denied but rather repudiated by Wittgenstein: "It is what human beings say that is true and false; and they agree in the language they use." That is to say, as words are deeds, ${ }^{3}$ and as we have already seen that to speak is to act and moreover that no action is independent of or outside a context (the notion of contextfree speech is self-evidently absurd), then agreement, and truth, could not hover above the world, uprooted from human practices or human language. Thus, Wittgenstein adds, "That is not agreement in opinions but in form of life." Like the language within which it is manifest, human agreement is not, in opposition to naive linguistic conventionalism, ${ }^{4}$ superficial. And in a quite different epistemological discussion, concerned with the function of doubt and what might be called the phe-

delivered at Cambridge University as part of the lecture series "Cambridge English" organized by George Watson, March 6, 1989 .

3. For a related discussion, see Peter Winch, "Im Anfang war die Tat," in Trying to Make Sense (Oxford: Basil Blackwell, 1987).

4. By "naive" I refer here to the presumption that words are arbitrary signs attached by convention to their otherwise disassociated meanings; I discuss this view in connection with aesthetics my "Language of Feeling," The Journal of Comparative Literature and Aesthetics (forthcoming). 
nomenology of knowing, ${ }^{5}$ Wittgenstein remarks, "Now I would like to regard this certainty, not as something akin to hastiness or superficiality, but as a form of life." And reflecting on what he has just said, as a way of further exposing its roots to human or lived practices, he adds, "But that [the previous remark] means I want to conceive it as something that lies beyond being justified or unjustified; as it were, as something animal."7 "Something animal" is not, presumably, going to float in a sphere of abstracted reflection and arbitrary agreement above and beyond the context of experience. And the next appearance of the phrase in Philosophical Investigations occurs at the opening of part II, in which we find a discussion of the mental life of, indeed, a dog.

Pursuing the question of why we can well imagine a dog frightened or startled but not hopeful, ${ }^{8}$ Wittgenstein gives us the example "A dog believes his master is at the door" (PI, p. 174). So far, so good, but this is immediately followed by the question "But can he also believe his master will come the day after tomorrow?" To say that the dog believes his master is at the door does seem unproblematic; this might occur where the dog, say, hears the sounds of an approaching person and shows all the signs of canine excitement, but in fact we know his belief is unfounded; it is the postman. Of course when we say this of the dog, as we might to explain his excited behavior to someone in the room, we don't mean that the dog formulated a proposition and corroborated it by inquiring into states of affairs in the world. Beliefs, the attribution of belief, the excitation of

5. I am not suggesting here that Wittgenstein is any kind of phenomenologist; this way of putting the matter simply seems properly to underscore the shift of focus from objective states of external affairs to the experience of certainty.

6. On Certainty (Oxford: Basil Blackwell, 1969), sec. $35^{8}$.

7. Ibid., sec. 359 .

8. Naturally Wittgenstein is interested in revealing something about the logic of the employment of the concept of hope, not about canine phenomenology. 
the dog, and our recognition of the dog's mistake do not in this way sever words from the world-or language from a form of life. But when we proceed to the next question, that is, whether or not the dog holds a capacity to believe its master will come in two days, we sense incoherence and find ourselves puzzled about how precisely to proceed. Thus Wittgenstein asks, "And what can he not do here?" where the "what" registers the frustration one feels at not knowing even how to begin to characterize the thing the dog cannot do. It is not that this particular dog cannot perform a certain feat, a feat within the capacities of some dogs but not this one, for example, jumping through a hoop. It is rather that the question insistently forces us to transgress the limits of the language-game, or, as we might now begin to see, to ask a question that does not have roots extending into known practice. Wittgenstein proceeds, leading us into the issue of mastering a technique: he asks, "Can only those hope who can talk?" And quickly answers, "Only those who have mastered the use of a language." That is, a language in the sense that Wittgenstein gives the term, not as it is understood in conventionalist theories of language. Such a (Wittgensteinian) language is rooted in a complex web of human practices where the employments of words themselves constitute some of those practices and itself engenders the mental and emotional phenomena of hoping. This formulation gives new application to and thus revives the claim made in the Tractatus Logico-Philosophicus:"The limits of language ... mean the limits of my world." "When that claim was first made, Wittgenstein meant something utterly different by "language." Now, in the late works, "language" must be understood instrumentally, connected with language-games, and, most important, as inextricably rooted in deeds. Thus Wittgenstein says, "Only those [can hope] who have mastered the use of a language"

9. Ludwig Wittgenstin, Tractatus Logico-Philosophicus, trans. D. F. Pears and B. F. McGuinness (London: Routledge \& Kegan Paul, 1961), 5.62. 
because "the phenomena of hope are modes of this complicated form of life."

The final appearance of the phrase "form of life" in Philosophical Investigations marks a point of convergence with multiple resonances. The nature of certainty, the limits of epistemological doubt, and the end of explanation are all present in the claim "What has to be accepted, the given, is-so one could say-forms of life" (PI, p. 226). We shall return to the more focused significance of the resonances; for the present we must look into the theme that this remark makes most salient, the immediacy, or specifically the nonmediated or unconsidered character of forms of life, and to pursue this matter we must look into the logic of gesture.

In his early comments on Sir James George Frazer's Golden Bough, ${ }^{10}$ Wittgenstein says, "We have in the ancient rites the use of a very highly developed gesture-language." With this remark he links the culturally deep practices of ritual with the concept of language by introducing the notion of a gesture language. Such a language of gestures might well constitute the paradigm case of a nonverbal language-game; that is, a set of moves embedded within a set of social practices that carry meaning - and in the case of rites, deep meaning - that nevertheless defy verbal or propositional formulation. It is true that the phrase "nonverbal language-game" seems selfcontradictory at best, but if we recall gestures $d o$ carry meaning, and that they often speak louder than the accompanying words, which might well be incompatible with them, the phrase is not as self-contradictory as it seems. Moreover, if gesture at its best or highest, ${ }^{11}$ that is, ritual, possesses meaning like language but

10. Rush Rhees, "Wittgenstein on Language and Ritual," in Wittgenstein and His Times, ed. Brian McGuinness (Oxford: Blackwell, 1982), p. 69.

11. This is not to say that it follows from respect for a ritual that it is thereby morally acceptable or that it should continue despite all costs and relevant particular considerations for evaluating it. See Richard Wollheim, The Sheep 
not within language, then we are indeed approaching a very promising analogy for the understanding of art.

In a remark in the Philosophical Investigations made in connection with the larger discussion of the perception of an agent's following of a rule Wittgenstein makes it clear that he sees the capacity for meaning in gesture as an illuminating aspect of linguistic meaning: "Suppose you came as an explorer into an unknown country with a language quite strange to you. In what circumstances would you say that the people there gave orders, understood them, obeyed them, rebelled against them, and so on?" (sec. 206). These actions are, of course, various individual moves available within this heretofore unknown language-game; and although they are individual moves (to give an order is not to rebel against it), they intersect within the practices of the people of this unknown country in such a way that an autonomous move, for example, giving an order without the interrelated possibility of its being understood, is inconceivable. Wittgenstein makes it plain on the next line that gesture, broadly speaking, as it occurs within that witnessed set of practices, is fundamental to our coming to understand those practices: "The common behavior of mankind is the system of reference by means of which we interpret an unknown language." That Wittgenstein links speech to gesture and not to abstract logic is reinforced in further remarks in the early manuscript on Frazer, ${ }^{12}$ in which he says, "Understanding negation is seeing the defensive gesture in it... understanding negation is the same as understanding a defensive gesture." 13

This association of linguistic meaning with gestural

and the Ceremony, Leslie Stephen Lecture 1979 (Cambridge: Cambridge University Press, 1979), esp. pp. 26-33.

12. This is reported by Rush Rhees in "Wittgenstein on Language and Ritual"; in what follows I am much indebted to both his discussion of this topic and his insightful placement of relevant passages and quotations.

13. Rhees, "Wittgenstein on Language and Ritual," p. 71. 
meaning ${ }^{14}$ not only emphasizes the roots of meaning as they run through human practices and contexts but also "depsychologizes" meaning: that is, gestural meaning made salient discourages linguistic mentalism. In art, liberation from the aesthetic analogue to mentalism can prove clarif ying on a range of artistic topics from creation to criticism. But before progressing beyond the topic of gesture in connection with the project of assembling a comprehension of the phrase "a form of life," we should glance at a few examples. Commonplace examples show the mutual reliance of the verbal and the gestural: "Shrugs, shakes of the head, nods, etc. are called signs principally because they are embedded in the way we use our spoken language." ${ }^{15}$ Concerning ritual, Rush Rhees says:

The ritual means something to those who celebrate or take part in it. Depending on which rite it is, there must be just these gestures, just these words must be uttered, and they must come in this order. What is done and spoken in the ritual refers to something important in the lives of the people who practice it: to sunrise at the solstices or equinoxes, to planting and harvesting, to the coming of the rainy season, to birth, to marriage, to burial, to going into battle, etc. It can do this, it has this significance because "it is the same language"- the language in which they plan and go about their sowing and harvesting, the language of their hopes and fears regarding it. ${ }^{16}$

Here it is clear that the particular actions of the ritual as properly performed, as deeds, are meaningful through their

14. See Norman Malcolm's discussion of a Neopolitan gesture indicating contempt performed by Piero Sraf fa and directed to Wittgenstein accompanied by the query "What is the logical form of that?" which Malcolm suggests "broke the hold on him of the conception that a proposition must literally be a 'picture' of the reality it describes," in Ludwig Wittgenstein: A Memoir, with a biographical sketch by G. H. Von Wright (Oxford: Oxford University Press, 1958), p. 69.

15. MS 116, 262; quoted in Rhees, "Wittgenstein on Language and Ritual," pp. $71-72$.

16. Rhees, "Wittgenstein on Language and Ritual," p. 72. 
connection with the hopes and fears of the participants. Rhees mentions a curiously powerful example of such a ritualistic practice (discussed by Wittgenstein from The Golden Bough), the "ceremony of adopting a child, in which the mother draws the child through her clothes." ${ }^{17}$ Rhees says of this case that it "is like a figure of speech; something like a description of actual birth, although a symbolic and abbreviated one. It is a figure which might have been used to tell of an actual birth; but this is not how it is in the ceremony. She is not describing what has happened or trying to tell anyone what it is like."18 Indeed, the gesture, seen from the right perspective, possesses a remarkable power and is, if anything is, laden with meaning. Yet, for all that implicit significance, it is not a form of putting forward a proposition, of making an assertion, of giving a description. This is a human practice, although like language in its richness of meaning, far deeper than that of merely telling. As a ritualistic action it possesses a meaning with roots running through hopes and fear, through thoughts and feelings, and is thus very much like language; it is not at all like a propositional theory of language.

Within the philosophy of language, however, we might well ask, if the analogy between language and art is to prove ultimately illuminating, have we been given a new candidate for the essence of language and linguistic meaning? Have we, indeed, encountered a claim, in some way still inexact, that gesture, where this is thought to be rooted in practice and an unmediated form of expression, is the essence of linguistic meaning? The answer, of course, is clearly negative. In Philosophical Investigations, section 92 , Wittgenstein writes, "This finds expression in questions as to the essence of language, of propositions, of thought-For if we too in these investigations are trying to understand the essence of language-its function, its struc-

17. Ibid., p. 73 .

18. Ibid. 
ture.-yet this is not what those questions have in view. For they see in the essence, not something that already lies open to view and that becomes surveyable by a rearrangement, but something that lies beneath the surface. Something that lies within, which we see when we look into the thing, and which an analysis digs out." ${ }^{19}$ To make the gestural power of language visible, and to do this by "rearranging" our philosophical expectations by bringing gesture and language into conceptual proximity and by showing the roots that gesture and ritual have in human practices and their resonances with thought and feeling, is precisely what the remarks on Frazer and investigations into gesture accomplish. But to go on to claim that gesture is, or may be, linguistic essence, is to succumb to conceptual relapse. This is indicated in Wittgenstein's next line "The essence is hidden from us': This is the form our problem now assumes." And analogously, in aesthetics, we would, succumbing to the same temptation, search for the hidden essence of artistic meaning. Going on, he adds, "We ask: 'What is language?', 'What is a proposition?' And the answer to these questions is to be given once for all; and independently of any future experience." In aesthetics, we would ask, "What is art?" "What is artistic meaning?" as though an answer could be provided not only in isolation from the artistic practices and contexts within which aesthetic gestures are significant but in isolation from, and prior to, any future experience of new artistic developments. Connecting language with gesture makes a number of features of language salient, features we would forget to our conceptual peril, but it does not make gesture linguistic essence. Still, to return to the example of the adoption rite, one might say that it $i s$ meaning-laden and that we want to know what it means apart from the description of the practice itself and its felt power. But this would be to insist that gestural meaning is, in

19. For a sustained discussion of Wittgenstein's own criticisms of the earlier view, see Norman Malcolm, Nothing.Is Hidden (Oxford: Basil Blackwell, 1986). 
the end, propositional. As Wittgenstein remarks in one of his manuscripts, "It is a great temptation, to try to make the spirit of something explicit."20

To attempt to render the spirit of the adoption rite explicit would be to see it as a function of some prior reasoning about its significance. In a discussion of the nature of certainty, Wittgenstein says, "I want to regard man here as an animal; as a primitive being to which one grants instinct but not ratiocination. As a creature in a primitive state." ${ }^{21}$ Such a creature would engage in practices that embody certainty but do not follow from reflection about the certainty they implicitly embody. Perhaps "instinct" is the proper name for such practices; the "primitive being" acts within a context, within a language-game, in which words and deeds are not ontologically distinct and in which the significance of those words and deeds, the range of which is circumscribed by the limits of the game, is not the result of epistemological reflection and the rational overcoming of doubt. Does such a primitive picture, itself suggested as a corrective to the more familiar, overly intellectual one, in its turn oversimplify the logic of language? Wittgenstein continues the above passage with "Any logic good enough for a primitive means of communication needs no apology from us." And, summarizing the point of these remarks, he adds "Language did not emerge from some kind of ratiocination." ${ }^{22}$ Thus the conception, the overview, ${ }^{23}$ of situated language that emerges from the pursuit of the meaning of the phrase "a form of life" is startlingly unlike the conceptions of language that have been

20. Quoted in Rhees, "Wittgenstein on Language and Ritual," p. 93.

21. On Certainty, sec. 475 .

22. See also $O n$ Certainty, sec. 477: "For why should the language game rest on some kind of knowledge?" Again, it is not prior thought that the moves in the game require for their sense. For the idea that language needs no foundation and that such a foundation would not in any case be what we expect it to be, see Wittgenstein, Philosophical Investigations, secs. 124 and 129.

23. By "overview" I mean one of the positive results of a philosophical investigation; I discuss this at greater length in the final section of Chapter 5 . 
traditionally influential in aesthetic theory; one can make this difference all the more explicit through the analogy between art and language by simply restating this claim: art did not emerge from some kind of ratiocination. ${ }^{24}$ But again, at this point we are still building another basis for the multifaceted analogy between art and language on the linguistic side of the equation; the parallel discussion of art and literature is yet to come. For the present, in the interest of further establishing the basis for the analogy, we must look further into the nature of the "spirit" that it is tempting to try to make explicit.

According to Rhees, in his second set of comments on Frazer's Golden Bough Wittgenstein could have expressed his point well by saying that Frazer, although perfectly capable of giving detailed accounts of the history and precise practices of the fire festivals, did not grasp the spirit, the Geist, of those ritualistic practices. ${ }^{25}$ Frazer's methodology committed him to grouping all the fire festivals of Europe together in one category. Of this search for commonality Wittgenstein commented, as Rhees reports, using the analogy of facial resemblance: "It is a wide variety of faces with common features... And one would like to draw lines joining the parts that various faces have in common. But then a part of our contemplation would still be lacking, and it is what connects this picture with our own feelings and thoughts. This part gives the contemplation its depth." Indeed, what the "picture" of the ritual presents, as that picture

24. Wittgenstein clearly meant this claim (as applied to language) as a corrective; the line of thought cannot be taken too far, as it is, for example, in the erroneous claim that all language replaces natural emotional expression, or (as applied to art) in the equally erroneous claim that all art is a replacement for natural emotive behavior. A more accurate way of setting out the artlanguage analogy at this juncture is to say that just as language did not emerge from ratiocination, art did not emerge from thought about the possible combinations and interactions of arbitrary signifiers.

25. Rhees, "Wittgenstein on Language and Ritual," pp. 93-97. See also Frank Cioff, "Wittgenstein and the Fire-Festivals," in Perspectives on the Philosophy of Wittgenstein, ed. Irving Block (Oxford: Basil Blackwell, 1981). 
is formed by tracing resemblances, is just what they have in common. And this strategy promises an understanding of the practices of precisely the sort that Frazer delivered, but systematically omits the connection to our feelings and thoughts, and thus fails to capture the spirit, the resonance, and the depth of the ritualistic practices. There is an all-too-common arthistorical methodology analogous to Frazer's study of ritual. This "positivistic" approach documents and verifies the technical details of the history of a work of art in terms of commodity exchange. Like Frazer's, such an approach misses that vital connection to thought and feeling.. Still, what can be said of this connection? ${ }^{26}$

Further into the discussion of ritual, Wittgenstein asks what it is that makes human sacrifice seem deeply sinister. He considers and rejects the hypothesis that this sinister effect is a direct function of the suffering and loss of the victim: "All manner of diseases bring just as much suffering and do not make this impression." 27 Apparently recalling the shortcomings of Frazer's account and reflecting on how very much the method of searching for external features common to many different ritualistic practices misses, he adds, "No, this deep and sinister aspect is not obvious just from learning the history of the external action, but $w e$ impute it from an experience in ourselves." In commenting on these remarks of Wittgenstein's, Rhees directs our attention to the particular expressions Wittgenstein employs which include the phrase "that which I see in those stories"28 and the phrase above, "this deep and sinister aspect." At a glance one can see here the clear connection with Wittgenstein's discussion of aspect perception and "seeing-as" (PI, part II, sec. xi). And within this glance one issue is vividly clear:

26. For an analysis of the parallel between the correspondence of (1) emotion with a natural scene and (2) emotion with a work of art, i.e., the connection of thought with feeling, see Wollheim, The Sheep and the Ceremony.

27. Rhees, "Wittgenstein on Language and Ritual," p. 100.

28. Ibid. 
a central theme of the remarks on aspect perception is that it is not possible to distinguish the "given" in visual experience (seeing) from the "interpretation" (or thinking) of that experience. Instead, the perception of an aspect of a thing seems to suffuse the perceived object with the thought. Rhees makes the crucial connection here between Wittgenstein's thoughts on ritual and on aspect perception by quoting the now well-known passage, "But what I perceive in the dawning of an aspect is not a property of the object, but an internal relation between it and other objects." 29 And what was missed, in Frazer's account, was the "spirit", that is, the connections between our thoughts and feelings and the ritual. This spirit, which gives a ritual its depth, is nothing other than the indivisible perception of the thoughts and feelings in that ritual. And in a perfectly analogous way, what gives the later works of Rothko, for example, their curiously engaging depth are precisely the thoughts and feelings we perceive in them. Thus it is not the outward, physicalistic description of a work of art that can account for its depth, its engaging quality, or the ideas, thoughts, feelings, social practices, ${ }^{30}$ or precedents that we find in it. It is, rather-and to this topic we shall have occasion to return in connection with literary interpretation-its spirit.

Wittgenstein said of the ancient rites that they comprise a "very highly developed gesture-language" and that the "ritual of the ancient myths was a language." ${ }^{31}$ We have seen that an

29. Ibid., p. 102.

3o. See Wittgenstein's remark, quoted in Rhees, "Wittgenstein on Language and Ritual," p. 106: "In all these practices we see something that is similar, at any rate, to the association of ideas and related to it. We could speak of an association of practices." For an example of one such association of practices in visual art, see Kirk Varnedoe's identification of the impulses motivating Picasso and Gaugin as primitive, in A Fine Disregard: What Makes Modern Art Modern (New York: Abrams, 1990), p. 185; see also Varnedoe's discussion of Aby Warburg's perception of the "root similarities" of European and primitive art, pp. 191-92.

31. Rhees, "Wittgenstein on Language and Ritual," p. 69. 
investigation into the meanings of the phrase "a form of life" itself constitutes an investigation into Wittgenstein's later conception of language. And it is clear that it is this conception of language which will prove illuminating in art as the basis for the analogy—or multifarious analogies-between language and art. But before turning directly to the application of this conception of language to art the conception itself still has to be more fully elaborated. Before pursuing that elaboration, it is worth commenting on one further aspect of the phrase "a form of life." This phrase, after all, incorporates metaphorically the concept of life, and with this metaphorical description of language we ought not to be surprised if, as a result of the analogical connection of art with language, we encounter a description of the power a work of art, as a perfect analogue to a human being, has to connect its "spirit" to thoughts and feelings.

\section{Gesture, Ritual, And Artistic "Spirit"}

It is clear that the phrase "form of life" is meant, in part, to prevent dualistic mentalism from influencing the shaping of a conception of meaning. Late in part I of Philosophical Investigations Wittgenstein suggests that one might distinguish between "surface grammar" (PI, sec. 664) and "depth grammar" in the use of words, but qualifies this suggestion by adding that what "immediately impresses itself upon us about the use of a word is the way it is used in the construction of the sentence." Thus, to rephrase, a word is an utterance defined by its instrumental function in a specific context and not an arbitrary signifier set against the background of a sentence. Moreover, as should be clear from the preceding, this context is not the result of our perception, but, as a form of life, it is a given. Wittgenstein continues by adding that what immediately, as 
opposed to mediately, strikes us is "the part of its use-one might say-that can be taken in by the ear."

Having established the instrumental employment of a word within a given context, Wittgenstein moves on to repudiate the very notion of depth grammar, showing how this notion is conceptually disorienting: "And now compare the depth grammar, say of the word 'to mean', with what its surface grammar would lead us to suspect. No wonder we find it difficult to know our way about." That is, having first been given a clear view of functional meaning within an immediately grasped context, we then utterly obscure this newfound understanding with the metaphor of depth and imply the existence of an intangible and ultimately hidden realm of "meanings." It is no wonder, indeed, that we then feel haunted by meanings we can sense but not articulate. Nor is such a haunted condition unfamiliar to the practitioners of aesthetics who having implicitly subscribed to the mentalism Wittgenstein is undermining, define the central task of aesthetic theory as the development of a method for pursuing such meanings. ${ }^{32}$ Does this emphasis on context thus imply that the meaning is on the surface? The answer to this question must be both yes and no: "yes" in the sense that the elucidation of the phrase "form of life" leads us to look at instrumental function within given contexts and not "beneath" them; "no" in the sense that the very distinction between surface and depth suggests that the operative concept of meaning as it is attached to surface-meaning and depthmeaning is acceptable, and that we must simply choose the former. But this conception is decidedly not acceptable, for reasons Wittgenstein makes clear in section $66_{5}$ : "Imagine

32. Much of the debate concerning the significance of intention for interpretation shares this mentalistic conception of the task of aesthetic theory; I discuss some cases in my "Artistic Intention and Mental Image," Journal of Aesthetic Education 22 (Fall 1988): 63-75. See also Colin Lyas, "Personal Qualities and the Intentional Fallacy," in Philosophy and the Arts, Royal Institute of Philosophy Lectures, vol. 6, ed. Godfrey Vesey (London: Macmillan, 1973). 
someone pointing to his cheek with an expression of pain and saying 'abracadabra!'-we ask 'What do you mean?' and he answers 'I meant toothache'." This is indeed a perfect illustration of the shallowness of the mentalistic, conventional understanding of meaning as somehow hidden behind or beneath the arbitrary word or sign. Surely rightly, Wittgenstein says next, "You at once think to yourself: How can one 'mean toothache' by that word?"... Or what did it mean to mean pain by that word?" Indeed, not only is the notion of the hidden meaning obscure, but it is not clear whether we can mean anything by this conception of meaning. "And yet," he then adds as a reminder of how familiar this conception of hidden meaning is to the philosophy of language, "in a different context, you would have asserted that the mental activity of meaning suchand-such was just what was most important in using language."

The aesthetic parallel is eminently clear: when discussed in connection with a particular artistic gesture in a particular context and style, meaning is vividly apparent. By contrast, when discussed as the hidden product of private mental intention, meaning is, as the target of criticism, disorienting at its very best. "But," one wants to insist, "can't I say By 'abracadabra', I mean toothache?" Wittgenstein answers, naturally, "Of course I can," but quickly adds, "But this is a definition; not a description of what goes on in me when I utter the word." The analogous lesson for aesthetics is equally clear: if an artist or writer means something by a particular work, and if we, as critics of that work, want to recover that meaning, we will not find it by trying to hunt down a hypothetical act of "meaning" that took place as the work was created or "uttered," but rather by looking to the particulars of the context within which that "utterance" was made.

Much earlier in Philosophical Investigations Wittgenstein remarks that for "a large class of cases-though not for all-in which we employ the word 'meaning' it can be defined thus: the meaning of a word is its use in the language" (PI, sec. 43). 
If to imagine a language is to imagine a form of life, and if art is in this respect like language, then, employing the word "use" broadly, the meaning of a work is its use within the form of life of the world of art.

Another aspect of Wittgenstein's later conception of language to which we must return Wittgenstein called the mastery of a technique. To the question of whether it would be possible for one man to obey a rule only once in his life, Wittgenstein answers, "It is not possible that there should have been only one occasion on which someone obeyed a rule. It is not possible that there should have been only one occasion on which a report was made, an order given or understood, and so on" (PI, sec. 199). Making this fact salient for the later, larger conception of language, he adds, "To obey' a rule, to make a report, to give an order, to play a game of chess, are customs (uses, institutions)." 33 Thus meaning has a public character or dimension, which implies a concern for context. He continues, reiterating the necessity of context for comprehension, "To understand a sentence means to understand a language. To understand a language means to be a master of a technique." The first assertion emphasizes that a sentence is uttered, not in the solitary mental world of a private rule-follower, but within a linguistic community. The second emphasizes that sentences are instrumental, and thus that a sentence is uttered in practice. He takes up this conception of unmediated and uninterpreted practice in following sections.

Wittgenstein identifies, in section 201 of Philosophical Inves-

33. The attempt to define art as whatever an institution of some sort calls art does not, of course, constitute a development of this point; that obeying a rule, making a report, giving an order, and playing chess are, in this sense, customs, uses, and institutions, does not mean that an essence is given to these activities by their "institutional" contexts. Moreover, even if such a classification were established the reasons or justifications for it would nevertheless remain utterly unexplained. See Richard Wollheim, "The Institutional Theory of Art," Supplementary Essay 1, in Art and Its Objects, pp. 157-66. 
tigations, within his larger discussion of rule-following, what has been referred to as a skeptical problem, ${ }^{34}$ that is, that we face a paradox in the realization that no action could be determined by a rule, "because every course of action can be made out to accord with the rule." And, conversely, if every course can be made to fit the rule then it can equally be made discordant with the rule. "And so there would be neither accord nor conflict here." So there is no determination of a particular action by a particular rule, because any action can be shown to be in accord with an infinite number of other rules; in short, no one rule can be designated as the determining rule for an action, and thus the accord/disaccord distinction loses its sense. But of this problem we see an objection to its very formulation quickly registered in the following remark pertaining to the infinite regression of interpretations of the rule as the rule variously determines its corresponding course of action: ${ }^{35}$ "It can be seen that there is a misunderstanding here from the mere fact that in the course of our argument we give one interpretation after another; as if each one contented us at least for a moment, until we thought of yet another standing behind it." Thus each interpretation, as an act of ratiocination on the relation between the rule and its corresponding action, quickly yields to a competing interpretation of that relationship, which in turn gives way to another, ad infinitum. "What this shows is that there is a way of grasping a rule which is not an interpretation, but which is exhibited in what we call 'obeying the rule' and 'going against it' in actual cases." Interpretation is, again, ratiocination, and

34. This skeptical Humean light on the issue is cast in Saul Kripke, Wittgenstein on Rules and Private Language (Oxford: Basil Blackwell, 1982); the argument that this way of putting the matter is alien to Wittgenstein's enterprise is found in G. P. Baker and P.M.S. Hacker, Scepticism, Rules and Language (Oxford: Basil Blackwell, 1984), esp. chapter 1, "On Misunderstanding Wittgenstein: Kripke's Private Language Argument," pp. 1-55.

35. This objection to the very formulation of the problem is one of the considerations the Humean construal appears to undervalue. 
as such exemplifies the very mentalism and psychologism that Wittgenstein opposes with his later conception of meaning. Hence, "there is an inclination to say: every action according to the rule is an interpretation." Simply put, if this is true, thought directs every action by providing a rule to govern that action. But according to Wittgenstein, "we ought to restrict the term 'interpretation' to the substitution of one expression of the rule for another." In this latter case, of course, thought is present behind action, although not in the way the mentalistic picture suggests. The thought is about the rule, normally obeyed or disobeyed in practice. Thus, the rule, not the action, is the actual subject of reflection, and is, when made manifest, an interpretation of the action rather than its governor. Thus following a rule is, in Wittgenstein's sense, participation in a form of life, or as Wittgenstein puts it in the opening remark of section 202, "And hence also 'obeying a rule' is a practice."

The aesthetic parallel to these linguistic considerations is surprisingly apparent if one looks in the right place, and this too further corroborates the conception of the world of art, through the analogy with Wittgenstein's later conception of language, as a form of life. Questions of rule-following are perhaps most accessible in musical composition. When Haydn or Mozart wrote a terminal cadence, that is, a harmonic conclusion in which the unresolved dominant comes to rest on the tonic, did they, as compositional ratiocination determining the course of harmonic action, say to themselves, "The dominant needs an internal tritone" or "The final tonic needs a prominent major third"? Surely not; only beginners do that, yet the compositional practices of Haydn and Mozart most assuredly embody those rules. ${ }^{36}$ Indeed, this is the musical analogue to

36. See Philosophical Investigations, sec. 224: "The word 'agreement' and the word 'rule' are related to one another, they are cousins." Here, one might say, Haydn and Mozart, through practice-embedded rules, agree. See my "Music and Imagination," Philosophy 61 (October 1986): 513-17, for specific examples. For an accurate treatment of the logically primitive nature of agreements in 
Wittgenstein's remark in section 219: "When I obey a rule, I do not choose. I obey the rule blindly." In the case of Stravinsky, there is a recent interpretation of his entire opus suggesting that in fact there is a large-scale coherence running throughout

judgment, see Anthony Palmer, Concept and Object (London: Routledge, 1988), pp. 90-106. Of Wittgenstein's imagined book on anthropology, he said it "would begin by stressing the central role of a particular way in which human beings agree in what they say and do in any endeavour to understand them in their different societies." Palmer maintains that this book would make salient "that agreement which in the Philosophical Investigations is said to be necessary if language is to be a means of communication, necessary, that is, for there to be societies at all." Communication in art would, naturally, to the extent that it is language-like in its origins and functions, require parallel agreements for there to be artistic activity in society at all. Palmer makes it clear that it is a special variety of agreement under discussion here-one that stands before or beneath ratiocination. The immediately relevant passage from Philosophical Investigations, which Palmer discusses, is "If language is to be a means of communication there must be agreement not only in definition but also, queer as this may sound, in judgements. This seems to abolish logic but does not do so" (quoted in Concept and Object; p. 88).

It is certainly worth noting here as well that in his description of F. B. Ebersole's Things We Know (Eugene: University of Oregon Press, 1967), Palmer says that through the employment of "devastating examples [Ebersole shows] that the attempt to understand human behaviour by beginning with something which is not human behaviour, but, as the older psychologists used to say, 'mere bodily movements' ... and interpreting them by setting them in a particular background is hopeless." Palmer then shows that "this was indeed, the way in which Strawson was constrained to think and speak about other people." As I have argued elsewhere, Joseph Margolis, through the explicit appropriation of the Strawsonian model, and Arthur Danto, through the atomism implicit in his theory and his reductive program reaching back to the "mere real thing," are similarly constrained to think of art in this way.

For helpful discussions of the value of examples for philosophical method, see R. W. Newell, Objectivity, Empiricism, and Truth (London: Routledge \& Kegan Paul, 1986), esp. "Reason and Particular Cases: John Wisdom," pp. 85-100, and Onora O'Neill, "The Power of Example," Philosophy 61 (January 1986): $5^{-29}$. On the issue of ratiocination in connection with consciousness, selfunderstanding, and the location of meaning in a form of life instead of in the mind of a speaker, see the stimulating essays by Jonathan Lear, "On Reflection: The Legacy of Wittgenstein." Ratio 2 (June 1989): 19-45, and "Transcendental Anthropology," in Philip Pettit and John McDowell, Subject, Thought, and Context, ed. (Oxford: Clarendon Press, 1986). 
his work, in that it depends for its harmonic generation on a heretofore undetected septatonic scale. ${ }^{37}$ The point here is precisely that a new interpretation has been given, because in the restricted sense as suggested above, the governing rule behind the harmonic practice is itself the object of contemplation. In plainsong and early monody one could insist that the rule of, quite simply, harmonizing nothing, leaving only unaccompanied melodic movement, is followed consciously and rigorously. Of course, any rational person sensitive to the dangers of critical anachronism would strongly object to this construction; monody was a musical practice and as the "given" conception of the music of the period, although perhaps in retrospect in accord with, surely did not follow any such rule. Debussy, as is well known, was severely reprimanded by his instructors for failing to follow the rules of harmony, or, better, the rules of harmonic practice of late nineteenth-century Paris. What then are his parallel harmonies, which satisfied only, as he put it, the rule of his ear, if not instances of " 'going against [the rule]' in actual cases?" In visual cases, such as the jarring recognition of incorrect proportion in the classical orders, we see-and here is one of the many similarities between ethical and aesthetic perception-the rule only when it is broken, for most examples of the laws of classic proportion do not demand or even invite reflection on the rule itself. Similarly, we would experience a shock in reading the literary genre of magical realism as realism, ${ }^{38}$ but the shock would subside as soon as we learned that realism of the magical variety does not accord with the temporal and ontological rules of realism; when we read each of these genres of fiction for what they are, the issue of rules sub-

37. See Pieter van den Toorn, Stravinsky and the Rite of Spring:The Beginnings of a Musical Language (Oxford: Oxford University Press, 1987).

38 . I mean here the shock or severe confusion that would occur in trying to take, for example, Borges's cases of creating a person over time in an episodic dream or of repeatedly opening a book and each time finding different things in it, as realistic depictions of actual states of affairs. 
merges-back into practice. ${ }^{39}$ In all such cases, where we are following not labored and tenuous work but rather the work of the master of an art form-indeed the master of many techniques-the issue of rules, not subject to ratiocination, remains embedded within an artistic form of lif $\mathrm{e}^{40}$

In a well-known passage meant to return the conception of rule-governed behavior from an infinitude of interpretations back to practice, Wittgenstein says, "If I have exhausted the justification, I have reached bedrock, and my spade is turned. Then I'm inclined to say: this is simply what I do" (PI, sec. $217) .^{41}$ This passage explicitly speaks to rule-following, but for that reason it is also significant for the understanding of interpretation, which is significant for the understanding of the directness of our perception of emotional expression and which is in turn significant for the understanding of our perception of emotional expression in art. Thus bringing us back into direct contact with the issue of facial expressivity, Wittgenstein introduces the topic "Consciousness in another's face," which he immediately follows with an example from actual practice: "Look into someone else's face, and see the consciousness in it, and a particular shade of consciousness. You see on it, in it, joy, indifference, interest, excitement, torpor, and so on." ${ }^{42}$ These are, naturally, examples of an uninterpreted or unmediated perception of emotive and human qualities and experiences, and as such are familiar experiences situated within our form of life. As a way of making their uninterpreted perception clear,

39. In this connection, see also Philosophical Investigations, sec. 154: "If there has to be anything 'behind the utterance of the formula' it is particular circumstances."

40. A failure to recognize this embeddedness promotes the belief that every verbal utterance necessitates an interpretation of a linguistic rule, which in turn nourishes neo-Lockeian varieties of linguistic relativism.

41. See also On Certainty, secs. 97-99, for further discussion of the "bedrock" metaphor.

42. Ludwig Wittgenstein, Zettel, ed. G. E. M. Anscombe and G. H. von Wright, trans. G. E. M. Anscombe (Oxford: Basil Blackwell, 1967), sec. 220. 
Wittgenstein asks, against their natural familiarity, "Do you look into yourself in order to recognize the fury in his face?" Against the background, the context, of familiarity he has just sketched, it is clear that any such introspection and analogical comparison would be extraordinarily unusual and, like the explicit consideration of rules, anything but the basis of the ordinary cases; indeed it is against the context of the ordinary cases that cases involving the explicit consideration of rules stand out. He then adds, as a parenthetical development of the philosophical view he is opposing and hence a further reminder of that view's capacity to generate nonsense, "And what do we want to say now? That someone else's face stimulates me to imitate it, and that I therefore feel little movements and musclecontractions in my own face and mean the sum of these? Nonsense. Nonsense,--because you are making asssumptions instead of simply describing. If your head is haunted by explanations here, you are neglecting to remind yourself of the most important facts." To be haunted by explanations, or by the demand for them, ${ }^{43}$ here as before is to feel an illegitimate need for explanation beyond description. To develop this a bit further, Wittgenstein poses the case in which someone says to another, "I see the look that you cast at someone else." If the person spoken to were to claim that the speaker did "not really see it [Wittgenstein adds], I should take that for pure

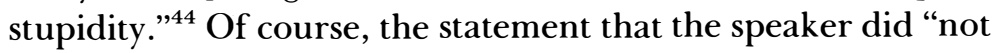
really see it" isn't stupidity, because it is consistent with the dualistic view, in which meaning is inwardly determined and

43. See Philosophical Investigations, sec. 21 : “(Remember that we sometimes demand definitions for the sake not of their content, but of their form. Our requirement is an architectural one; the definition of a kind of ornamental coping that supports nothing.)" An account of the demand in criticism for such "architectural" explanations of artistic meaning is given in my "Creation as Translation," Journal of Aesthetics and Art Criticism 46 (Winter 1987): 249$5^{8 .}$

44. Zettel, sec. 223 . 
emotional expression is encoded into physiognomy and decoded through analogical interpretation. It is, however, erroneous. The point is that according to the form-of-life conception of meaning, such acts of interpretation, in rulefollowing and in emotional perception, are conspicuously absent. Locating the aesthetic analogue to this discussion requires no searching; an entire world of art full of stylistically variegated depictions of human facial expressivity requires for its emotive impact no analogical imaginings of a diagnostic nature. This is, simply put, a matter of what we do not do, and in this connection Wittgenstein adds, "We do not see facial contortions and make inferences from them (like a doctor framing a diagnosis) to joy, grief, boredom. We describe a face immediately as sad, radiant, bored, even when we are unable to give any other descriptions of the features.-Grief, one would like to say, is personified in the face." ${ }^{, 45}$ And, to make clear that these considerations are not merely reflections on what we happen to do or not in actual practice quite apart from any more philosophically elevated enterprise, Wittgenstein adds the pointed remark "This belongs to the concept of emotion." It is selfevident that the concept of emotion holds direct significance for our understanding of art, and it is to cases of such understandings that we should now turn. ${ }^{46}$

\section{Meaning and Artistic Uses}

Roughly fifteen thousand years ago a person painted a picture of a bison on a cave ceiling in what is now Altamira, Spain. Such paintings have given rise to a good deal of speculation. One hypothesis is that the making of a picture of a bison was

45. Ibid., sec. 225 .

46. For a full discussion of the value of such a turn to cases, see O'Neill, "The Power of Example." 
thought to yield a power over the living bison such that it could be killed; such a conception is obviously primitive and, indeed, what we might call magical. But for this primitive conception of magical causation, and of the power of mimetic depiction, it is a fascinating explanation, and the fascination lies not in a form of meaning hidden "beneath" the painting, but in the role visual representation-as we retrospectively call it-played in the lives of those cave dwellers. And of course, this explanation also makes clear that the power of depiction was instrumental; like voodoo practices, ${ }^{47}$ it is the making of the depiction or the representation, and the ritualized acting on that depiction, that holds the power.

The introductory bassoon passage of Stravinsky's Rite of Spring is now widely misunderstood. ${ }^{48}$ That its texture and its rhythmic ambiguities are aurally engaging, that they "grab the ear," as it is sometimes put, is obvious on the auditory "face" of the passage. But at the time Stravinsky wrote it, the extended upper range of the bassoon that is commonplace today was then unknown. As a result the original performance had a very tenuous and strained quality; indeed, anyone with a knowledge of the then-limited upper range would have listened, as we say, on the edge of the seat. The effect would have been roughly like that of hearing a mezzo-soprano take the soprano part and perform, although successfully, at the very limits of the possible. Knowing this transforms our perception of that introductory passage and allows us to hear it as a gesture at the limit of the expressive reach of the instrument. ${ }^{49}$ And to understand that musical gesture properly is to see it in its initial context.

47. The similarity of function in these cases is mentioned by Susan Woodford, Looking at Pictures (Cambridge: Cambridge University Press, 1983), p. 7 .

48. This case of instrumental range and the importance of original context for comprehending meaning was presented by Alexander Goehr in the lecture "Music and Communication" in the Darwin Lectures, Cambridge University, February 24, 1989 .

49. I put it this way, i.e., hearing it $a s$ an instrumental gesture at the limits 
In Philosophical Investigations, section 207, Wittgenstein remarks that it is the "common behavior of mankind" that serves as "the system of reference by means of which we interpret an unknown language." He continues, "Let us imagine that the people in that country carried on the usual human activities and in the course of them employed, apparently, an articulate language." On first hearing a performance of Elliott Carter's works for solo tympani, one finds oneself in an analogous position. It seems, at first, beyond intelligibility; then it seems to approximate coherence. Later, the performance seems to present an articulate language, and in the end one might well marvel at how articulate, throughout the expressive range and limits of the tympani, those works actually are. This process is not only aided by the context of the "common behavior" of musical coherence, which elicits our expectation of hearing, and our willingness to listen for such coherence, but also by "systems of reference" of rhythmic structure and repetition, pitch variation, and dynamic variation. And if we initially face, on first hearing those remarkable works, a question of meaning, it is a focused question asking for precisely this kind of progress toward intelligibility.

Within the context of Greek architecture the fact that there is a difference between Doric and Corinthian column capitals is of course significant. The Doric betokens purity and directness; the Corinthian, an increased concern for decoration and perhaps visual embellishment. And within this context, if one wanted to argue further for the distinction as it is here characterized, one could point to the other ends of the columns. The Doric stands directly on the stylobate; the more florid Corinthian meets a softening base before reaching the floor. These columns have been employed in a radically divergent context,

of its range because, of course, it no longer is; yet to hear it properly we must use our imaginations to hear it precisely in this way. In brief, knowledge of the context here transforms what we hear. 
that of postmodern architecture, and in these uses of the Greek visual "utterances" there is, against the immediately preceding antihistorical modernism, a re-embracing of historical precedent. But the use of either the Doric or the Corinthian now carry that significance, in that both are certainly integrative gestures of our visual history and perhaps nostalgic in a selfconscious way. In the initial context, the difference between the two was crucial for their significance. In the present context, in which the additional meaning of historical eclecticism is now a possible move within the expanded stylistic game, they have similar meanings because they have very similar uses.

In Section 441 of Philosophical Investigations, Wittgenstein begins, "By nature and by particular training, a particular education, we are disposed to give spontaneous expression to wishes in certain circumstances," and a moment later adds, "In this game the question whether I know what I wish before my wish is fulfilled cannot arise at all." The context of modern jazz improvisation is a certain circumstance within which one gives spontaneous expression to musical ideas, where this capacity is a function of a particular training and education, but the question of whether or not the players know what they wish before the wish is fulfilled transgresses the limits of the game (the practices of an improvisational ensemble), because the dualistic scheme the question implies is not operative in the first place. It is, indeed, a question that cannot be answered, because its formulation is incoherent at worst, inapplicable to the case at best, and leads us to believe that the "meaning" of the improvisation must in a mysterious way lie behind the sonic surface in the private intentional world of the improvisers.

In Jackson Pollock's large action canvases we encounter visual surfaces that almost invariably provoke questions of meaning. This question is very often answered within the concept of "action" itself. These canvases are the visual analogue to a taperecording of a concert; that is, they reveal what happened when they were created. And this in turn provokes, in further pursuit 
of meaning, the question of how they were made, and the processes of dripping, throwing, hurling, and so on are then described. It is in this connection that the frequent reproduction of the photograph of Pollock at work, standing over a canvas with brush and not palette but bucket in hand, is the visual answer to the question of meaning provoked by the canvases. (What other photographs of painters at work are in fact widely reproduced?) More considered questions of meaning lead to an inability, in Pollock's case, to distinguish between deliberation and execution, between form and content, between design and spontaneity, and between movement and stillness. And with titles such as "Autumn Rhythm," one might argue, in the continued inquiry into meaning, that the distinction between abstraction and representation has also been blurred. All of these considerations concern directly, immediately, and unmysteriously, the practices of an artist within the larger conceptual web, or aesthetic context, of these distinctions.

Roy Lichtenstein has produced a body of paintings that are generally construed as large-scale cartoons, with ballooncaptions such as "I'd rather drown than call Brad for help...." But they are, of course, not large-scale cartoons, they are largescaled detailed depictions of cartoons, and as such require the deliberate and exacting duplication of a number of features that are, at the relatively miniscule cartoon scale, accidental or inadvertent. For example, the stroke of a brush or a pen is, at a fine level, uneven; there are streaks and lines contained within the stroke that are functions not of deliberation but of the medium itself. Lichtenstein painstakingly duplicates such internally contained lines, and thus, through a dramatic change of scale, expands the "reach" of the intentional within the image; that is, he pulls the accidental visual features into the realm of the deliberate-and skilled-moves of the visual game. In short, this work might be characterized as a thoroughgoing commitment to the depiction of the accidental. But of course this aspect of his work is frequently missed, precisely because 
of its success in this escalation of scale. And we are, of course, further blinded to this aspect because of the ubiquity of actual cartoons throughout society, and it is thus tempting, but erroneous, to dismiss Lichtenstein's paintings just as easily. Lichtenstein, however, addresses this point too, that we are often ready to dismiss the popular, and such an address is possible only within a context in which cartoons proliferate.

Robert Rauschenberg produced a series of works illustrating Dante's Inferno. One way to describe what takes place in that series of images is that two forms of life converge. It is true that in Dante's work itself, one misses a very great deal of the meaning of that text if one is oblivious to the Florentine politics of the day, precisely because Dante settles scores by placing his enemies in positions within the Inferno appropriate to their misdeeds. Similarly, if one is blind to the theological aspect, and especially the influence of philosophy in general and Aquinas in particular on the shaping of Dante's mind, one misses the literary portrayal of theological distinctions. And of course, if one overlooks the design, and fails to notice, say, the number of cantos or the use of terza rima, one then misses the mastery displayed by Dante through his power to express himself forcefully and evocatively within the limits of self-imposed formal constraints. Likewise, if one looks at one of Rauschenberg's illustrations without knowing the specific cantos to which they refer, one looks without seeing. And if one then further wants to add comprehension to vision, one must add the sociopolitical, theological, and formal aspects mentioned above in such a way that one finds parallels between the visual text of Rauschenberg and the verbal text of Dante. Each of these parallels mark a point of convergence between two forms of life, that is, Dante's Florence and Rauschenberg's New York, with the result that a new location for artistic meaning is developed. And within Rauschenberg's Dante, it is difficult to imagine any specific question of meaning arising that would not find its answer in one of these points of convergence. 
In the sixteenth century Bronzino painted a remarkable visual commentary, indeed a visual text, on what must have been for him or for his audience the salient moral aspects of love. The Allegory ("Venus, Cupid, Folly, and Time") presents in the center an appropriately unclad goddess of love suggestively embracing a similarly disrobed winged Cupid, who in turn delicately caresses temple and breast. To the right is a cherubic boy, representing Plèasure, who looks on in admiring and happy oblivion to what surrounds the central pair. The surrounding figures are a young female figure in a fine green dress, with a quiet, beautiful face but the lower body of a serpent (symbolizing Deceit), a distraught old woman holding her head and tearing her hair (symbolizing Jealousy), Father Time holding back one side of a blue curtain (symbolizing the unveiling powers of time), a goddess opposite Time who is holding back the other side of the curtain (symbolizing Truth), and a pair of masks (symbolizing the distinction between appearance and reality as it applies to this sort of case). First, as with Rauschenberg's illustrations of Dante, if one does not recognize the allegorical references in this work, one simply does not grasp its meaning. Second, the resonance this language has is a function of the experience of the viewer, or, in short, the "common behavior of mankind." Third, that such a theme was both amusing and aesthetically legible to Bronzino's society tells us about that society's sense of humor and, through this, of its concerns. Most important, however, is the process of interpretation itself. One sees first and immediately, and not as a function of interpretation, hypotheses-formation, or any visual analogue to the forming of a medical diagnosis, that it is a female figure in the center, a winged-boy next, and so on. It is after this foundation is secure that interpretation begins, and this is, indeed, a process of reflection on the "rules" associating the figures with their allegorical significance. The immediate perception is, as Wittgenstein said of the foundational following of rules, "blind"; only later do we begin the process of reading the visual text. 
Mondrian produced a well-known group of works in the interest of capturing the purity of Platonic essences. He pursued this goal not in the realm of Ideas but rather on canvas. And on canvas we find not the record of an internal struggle between the mere particulars of things and the Forms of those things themselves but rather designs of great geometric clarity. And these designs are filled with (appropriately) "pure" color. In short, this style of visual purity and clarity, elucidated with a force such that any move threatening or eroding that clarity would be instantly recognized for what it was, an affront to visual essence, was developed within a larger artistic context in which geometric clarity, purity of color, and a narrowly circumscribed range of hard-line abstract gestures were all significant, not only for what they committed to canvas and thus to visual experience, but for what they left out as well. What is present pursues essence and perfection. What is absent, which carries in these works of Mondrian the greatest significance, can only be discerned by placing the work against a background context within which these gestures are striking gestures for purity.

In a manner similar to the merger effected by Rauschenberg of late medieval Florence with twentieth-century Manhattan, Rembrandt produced the deeply engaging painting Aristotle with the Bust of Homer in 1653. Aristotle seems to be looking at the sculpted bust, but the bust itself is unseeing; the great blind poet's eyes are lost in the chiaroscuro darkness, and we realize that this darkness is itself sadly and mimetically fitting. Now looking back to the facial expression of Aristotle, we see that his expression is here, as Homer's must be, inwardly directed. It is a state of contemplation that is both inwardly focused and outwardly indicative of the experience of loss. And to see the resignation here portrayed on the author of the Nicomachean Ethics is to also see Rembrandt seeing that expression. As Wittgenstein put it, "Look into someone else's face, and see the consciousness in it, and a particular shade of consciousness. You 
see on it, in it..." On Aristotle's face we see the resigned contemplation born of both experience and reflection, and in Aristotle's face we see Rembrandt's depiction of that state; to underscore this connection we see that Aristotle is dressed in the garb of Rembrandt's time. Indeed, we see Rembrandt portraying Aristotle's "look" at Homer, which as just described reflects from Homer back to Aristotle, and back to Rembrandt, and-if we do find the work engaging - to ourselves. Here hypotheses that evoke the contractions of facial muscles to explain our perception are as crude as they are obtuse. And if we are "haunted by explanations here," we have indeed neglected "to remind [ourselves] of the most important facts," that when we see emotions, we see emotions and not facial contortions on the basis of which we infer emotions.

In Rembrandt's Aristotle we see the depiction of an emotion readily available to us; it is not the case that this expression communicates something hidden from us because of its belonging to a distant or remote historical period. Michael Baxandall has demonstrated, both verbally and visually, how in some cases the significance of expressions can in this way be hidden or obscured.$^{50}$ He provides an account of Fra Roberto's delineation of five successive mental states that Mary, as depicted in Annunciation paintings, should exemplify: Disquiet, Reflection, Inquiry, Submission, and Merit. These "Laudable Conditions" of the "Angelic Colloquy," as Fra Roberto puts it, ${ }^{51}$ once explained and thus acquired as categories within which to shape our visual experience to the original context of the image, have the power to transform our perception of the paintings Baxandall discusses. Simply put, these categories of emotional experience render the depicted expressions immediately recognizable; the initial uncertainty we may feel is thus

50. In his Painting and Experience in Fifteenth-Century Italy (Oxford: Oxford University Press, 1972).

51. Ibid., p. $5^{1 .}$ 
not a fact about the need for analogical hypotheses or, indeed, a concept of expression, but rather a fact about what might be described as the emotional distance of a cultural atmosphere permeated by theology. In the case of Botticelli, the errors here become more interesting than the successes, because the naturally emotive gestures depicted fit not a proper miraculous setting, but rather, as Fra Roberto continues, that of "an angel who, in making the Annunciation, seemed to be trying to chase Mary out of her room, with movements showing the sort of attack we might make on some hated enemy; and Mary, as if desperate, seemed to be trying to throw herself out of the window." ${ }^{52}$ Human bodily and facial gestures display a power of natural expressivity and significance that overpowers a mere contextual relocation. Gestures, above, were pursued in the interest of bringing out the nonmediated or unconsidered or indeed "animal" characteristic of a form of life, and in that discussion we saw the similarity between understanding negation and understanding a defensive gesture. Botticelli, we might say, has made Mary, within a gesture language, too much concerned with negation.

Wittgenstein says of the ancient rites that they are "a very highly developed gesture-language," and we placed that remark within the larger elucidation of the concept of a form of life. Baxandall also shows in a discussion closely related to the preceding that, to cast the matter one way, fifteenth-century Italian religious painting constitutes a highly developed gesture language. Baxandall quotes relevant instructions for a gesture language from an early sixteenth-century source, in which it is expressly stated that if the matter is solemn, stand upright and point with the forefinger; if cruel, bend the fist and shake the arm; if heavenly, look up and point toward the sky; if gentle, mild, or humble, lay the hands upon the breast; and if speaking of any devotional matter, hold up the hands. With the knowl-

52. Ibid., p. $5^{6 .}$ 
edge of these expressive conventions, our comprehension of the paintings of Carpaccio, Fra Angelico, Perugino, Pinturicchio, and Botticelli are transformed; what we see is illuminated by what we know, and this knowledge of gesture is, as Baxandall puts it, "a necessary part of looking at Renaissance pictures." 53 The ancient rites possessed a depth that although resistant to propositional encapsulation, both connected thoughts and feelings and exuded a "spirit." With even only a preliminary awareness of the social context of Renaissance painting, we can see that some Renaissance religious painting functions in precisely the same way. We saw earlier Wittgenstein's claim that to "understand a sentence means to understand a language." Here, to understand a gesture means to understand the larger gesture language, the context, in which it functions and operates, in which it has a use.

Raphael's great visual summa of Renaissance mental life, The School of Athens, has as its center the gesturing figures of Plato and Aristotle. The seeker of transcendental essence, the defender of the realm of ideas available only to the abstract intellect beyond the lower sphere of sensory particulars with their epistemological distractions, looks to his successor with a confident, or indeed knowing, upward-pointing gesture. Aristotle looks with equal confidence back to his predecessor with an outstretched and, indeed, moderating gesture, pointing, as it were, to this world. For a defender of the priority of particulars this is indisputably the correct response. But the ideological debate here graphically depicted is understood by knowing something of the influence of these classical authors in Raphael's Florence, and-to state the matter generally-the context within which such gestures are embedded. We saw above, in connection with language, the claim that truth does not merely "hover" above the world and appear as a function of superficial human "agreement in opinions," but rather that with roots

53. Ibid., p. 65 . 
extending deeply into the practices of a culture, it is "agreement" in form of life. Raphael has found a way to evoke visually, through gesture, what is here indeed a disagreement, and to do this he also evokes, at a deeper level, the agreement in form of life making the metaphysical opposition and its gestural expression possible: Much later, Jacques-Louis David reiterates, in his own way, this visual appropriation of the power of gesture in the The Death of Socrates; in this painting we see Socrates reaching for the hemlock unhesitatingly with one hand, and, to give comfort and reassurance to Phaedo, the jailor, Crito and the other witnesses, pointing confidently upward with the other. Here we see the significance if we first know the narrative history of this event from Plato's Phaedo, which stands behind the visual history presented here. And we see concerned, compassionate, pained, resigned, and confident expressions beautifully captured by David not mediately, as a consequence of emotive hypothesis-formation, but immediately, as an agreement in a form of life.

That examples could be continued indefinitely is not, I believe, accidental; that examples seem either to embody various detailed aspects of the phrase "form of life" as it is developed in Wittgenstein's philosophy, or that they, in a multitude of distinct ways, enforce the prerequisite of contextual placement for their understanding, itself argues for the contouring of the understanding of art according to our understanding of language as rooted in social practice. To fathom the work in the vanitas genre, and to feel almost tangibly the significance of the memento mori, is to possess a sense of mortality. To comprehend the power of Masaccio's Expulsion is to just see, as the end of. explanation, the expression of irretrievable loss within the context of theology; for its perception actual belief is not necessary, but the ability to imagine that belief most definitely is. If one can understand the possibility of the weariness of the visually sensitive at the culture-wide onslaught of advertising images, one can connect the multiple images of a Campbell's soup can 
to thought and feeling; moreover, insofar as the critical commentary conveyed by that multiple image suggests that things might be otherwise, that is, that we need not remain the passive receptors of such an onslaught, it thus functions like the "mastery of a technique" that makes hope possible. To recognize the conflicts of divergent conceptions of time, geological, theological, human, animal, immediate, and so on, is part of what is necessary to employ the concept of time, which is in turn necessary to the interpretations, in different ways, of the romantic fascination with ruins, the postmodern employment of the appearance of the weathered, and, specifically, Dali's Persistence of Memory. Understanding Giotto's Betrayal (The Kiss of Judas) reaches into our knowledge of the unmediated expressive significance of a kiss and, with the understanding of such gestural immediacy as a basis, the terrible moral vacuity of the reduction of that gesture to a mediated, deliberated signal, a convention for betrayal. ${ }^{54}$ Here too, although one must know much from human life to comprehend the painting, one need only be aware of the theological content of the painting; it is not necessary to endorse that theology oneself. Again, what is necessary is a capacity to imagine entering into the form of life.

Baxandall, referring to the intrinsic limitations of a purely documentary approach to understanding art, says that such studies "cover some kinds of activity and experience repetitively and neglect others. Much of the most important experience cannot conveniently be encoded into words or numbers." Thus an attempt to encapsulate propositionally the "spirit" systematically misses its mark. He adds, "It is very difficult to get a notion of what it was to be a person of a certain kind at a certain time and place," and against this epistemological difficulty places the remark "It is here that pictorial style is helpful." I would extend this to say that all artistic styles help us learn in precisely this way, provided we accept the invitation they extend

54. See Rhees, "Wittgenstein on Language and Ritual," pp. 95-96. 
to enter them imaginatively, to make an effort to comprehend what it was to be a person of a certain kind at a certain time and place. And this capacity to enter imaginatively an artistic form of life is remarkably like the deeply analogous case of the linguistic capacities to express, to comprehend, to appreciate significance, and to recognize the "spirit" of an utterance. ${ }^{55}$ Earlier, we considered, in connection with what was there called the phenomonology of knowing, Wittgenstein's remark "I would like to regard this certainty, not as something akin to hastiness or superficiality, but as a form of life." Capacities for expression, for comprehension, and for the grasping of significance and of "spirit" ought to be regarded in exactly the same way. Taken this way, such capacities themselves weigh against the floating or "hovering" shallowly conventionalist explanations, which themselves both exemplify the belief that language can mean anything the user or receiver wants and, correspondingly, that works of art can mean anything the perceiver sees in them. ${ }^{56}$ Indeed, although we can imagine a simple

55. It might be pointed out that this is, if in modernized form, not so far from the conceptions of the sympathetic imagination and empathetic understanding as developed in the eighteenth-century moral sense school in which imaginative "entry" takes place in the ethical rather than the aesthetic sphere.

$5^{6}$. To think of the arts as codes or as carriers of "information" attached to various physical media is shallow linguistic conventionalism. Michael Tanner's remark on significance beyond vocabulary and syntax makes it clear that we should avoid such reductive simplicities: "One may feel, reading poetry in a foreign language, that even though one has a mastery of the vocabulary, syntax, and even to some extent the idioms of the language, one is still bound to miss much of the significance of the poetry, because the only way to grasp it is to have spoken the language from the start, living in the community that speaks it" ("Objectivity and Aesthetics," Proceedings of the Aristotelian Society, supp. vol. $4^{2}$ [1968]: 72). In this connection we might recall that it is more than speech alone that is referred to by the term "language-game"; see Philosophical Investigaitions, sec. 7: "I shall also call the whole, consisting of language and the actions with which it is interwoven, the "language-game.". More extremely, in On Certainty, sec. 220, we find: "Our talk gets its meaning from the rest of our proceedings." And further underscoring the fact that speaking is a form of activity situated within a human context, in Philosophical Investigations, 
code or a floating set of conventional signals-like the superficial agreement on the identifying meaning of Judas's kiss-as a "language," to imagine an actual language, with its multiplicity of uses, its ritual-like connections to our thoughts and feelings, its rootedness in social practices, its mediated and unmediated employments, and its multitudinous varieties of expressivity, comprehension, significance, and nonexplicit spirit, or in brief its varieties of meaning, is indeed to imagine a form of life.

sec. 23: "The word 'language-game' is here meant to emphasize that the speaking of a language is a part of an activity or a form of life." 